\title{
Spread of chikungunya from the Caribbean to mainland Central and South America: a greater risk of spillover in Europe?
}

H Noël (h.noel@invs.sante.fr) ${ }^{1}$, C Rizzo²

1. French Institute for Public Health Surveillance (Institut de Veille Sanitaire; InVS), Saint-Maurice, France

2. National Centre for Epidemiology, Surveillance and Health Promotion, National Institute of Health (Istituto Superiore di Sanità; ISS), Rome, Italy

Citation style for this article:

Noël H, Rizzo C. Spread of chikungunya from the Caribbean to mainland Central and South America: a greater risk of spillover in Europe? . Euro Surveill. 2014;19(28):pii=20855. Available online: http://www.eurosurveillance.org/ViewArticle.aspx?Articleld=20855

Article submitted on 15 July 2014 / published on 17 July 2014

After a decade of outbreaks in Africa, the Indian Ocean and Asia, chikungunya virus (CHIKV) is stepping out of the shadow of dengue virus [1]. Although these two mosquito-borne viruses share clinical characteristics and their main vectors, Aedes albopictus (the tiger mosquito) and Ae. aegypti, CHIKV has long remained exotic to the western hemisphere [2]. The emergence of the Indian Ocean lineage changed the views on CHIKV when it caused an unprecedented disease burden in India and the islands of the Indian Ocean between 2005 and $2008[3,4]$.

More than the reports of single events of locallyacquired cases of chikungunya fever in Italy and France $[5,6]$, the recent occurrence of autochthonous transmission of CHIKV in the Americas has redesigned the geographic distribution of the virus. An outbreak in the Caribbean caused by an Asian strain of the virus started in Saint Martin in October 2013 with Ae. aegypti as the primary vector. The dynamics of the spread of CHIKV was in line with that in outbreaks that occurred in the Indian Ocean [2].

In this issue of Eurosurveillance, Cauchemez et al. estimate the basic reproductive number (the mean number of new host cases generated by one infectious host in a completely susceptible human population) at between 2 and 4 in the initial phase of the outbreak in the French Caribbean [7]. This is close to estimates from the outbreaks in Italy in 2007 and on Réunion Island in 2006 (3.5 and 3.7, respectively) $[8,9]$.

Data from epidemiological surveillance suggest that so far, six months after its introduction to the Caribbean, CHIKV has been responsible for over 350,000 suspected cases of chikungunya fever that have occurred throughout the region [10].

The consequences of the outbreaks in the Caribbean have ripples in Europe, as Paty et al. and
Requena-Méndez et al. document in this issue $[11,12]$. Paty et al. report the increased detection through surveillance of infected travellers arriving in mainland France from the French West Indies [11]. Likewise, the importation of chikungunya cases presented by Requena-Méndez et al. in this issue are likely to continue for months in Spain and other countries with intense exchanges with South America [12]. Cauchemez et al. stress that if circulation of CHIKV settles in mainland South and Central America, the international spillover of cases could escalate [7]. At this moment, public health surveillance has already detected local transmission of CHIKV on the continent, in Costa Rica, Guyana, El Salvador, Suriname and French Guiana [10].

Based on the recent rapid risk assessment from the European Centre for Disease Prevention and Control (ECDC), the chikungunya epidemic in the Americas represents a tangible threat to public health in Europe that goes beyond the scope of travellers' health [13]. In this globalised world, it could ignite local diffusion of CHIKV in Madeira that is colonised by Ae. aegypti and in the constantly expanding areas in Europe where Ae. albopictus is established. Vector competence studies are ongoing, but it is highly likely that Ae. albopictus will be found competent for transmission of the CHIKV strain circulating in the Caribbean. Local tiger mosquitoes were able to transmit CHIKV strains of the Indian Ocean lineage to more than 250 cases in Italy in 2007 and to two cases in France in $2010[5,6]$.

Local foci or even large outbreaks are more likely to occur in Europe now because of the synchronicity between CHIKV transmission on the other side of the Atlantic and the season of vector activity in Europe. Preventing the spillover of the chikungunya outbreak to Europe in this challenging context requires the mobilisation of the population and cross-sector collaboration between clinicians, medical biologists, entomologists 
and public health professionals at local, national and European level in as part of the One Health concept.

The odds of controlling CHIKV dissemination to Europe will become lower if, as expected, CHIKV spreads during the summer to continental South America. Indeed, it is plausible that the long feared epidemic in South America will be ongoing for months and maybe years, continuously fuelling the flow of imported cases.

There are no prospects of a human vaccine or curative antiviral treatment available in a near future. Therefore, the only opportunity of preventing dissemination to Europe consists in reducing the vector density and its contacts with humans. People living in an area colonised by Aedes vector mosquitoes should be taught how to prevent and eliminate man-made breeding sites to reduce the overall vector density around their homes and workplaces. They should be informed about personal protective measures to avoid mosquito bites such as wearing long-sleeve shirts and long trousers and using repellent on exposed skin. Travellers should strictly observe the recommendations for personal protection against mosquito bites while visiting areas where CHIKV transmission is active. In case of fever upon return to an area where the vector is established, travellers should seek medical attention and prevent mosquito bites while symptomatic. Because both vector mosquitoes are day biters, nets are of limited use. But they can be useful to protect in particular young children and infected patients that are resting. Healthcare professionals should become increasingly aware of the clinical presentation and diagnostics of chikungunya, as well as treatment relieving symptoms. They should advise travellers and cases about protective measures against mosquitoes.

Vector control measures should target both adult mosquitoes and larvae and rely on a limited set of insecticides that are active against Aedes spp. These insecticides should be used sparingly and only for targeted responses so as to avoid toxic effects on humans and the surrounding fauna as well as the emergence of resistant insects. For this reason, implementing surveillance systems for local entomological indicators in Europe is crucial in order to estimate the risk of local transmission associated with imported cases and to guide vector control measures in time and space.

Thus, it is crucial to be prepared. European Union (EU) Member States are advised to develop preparedness planning for identifying new health threats at national level according to the recent Decision 1082/2013/EU on serious cross-border threats to health [14]. The CHIKV control measures at EU level require: entomological surveillance, surveillance of imported and autochthonous cases and rapid diagnosis to detect local outbreaks. Moreover, vector control measures should be included in the planning around cases, either after rapid diagnosis or, in patients returning from epidemic areas, without waiting for laboratory confirmation results.

However, underreporting of cases can be substantial. Published reports suggest that the estimated number of imported cases generally exceeds the number of notified cases by a factor 10 and over $[15,16]$. Active mobilisation of clinicians and medical biologists in targeted geographical areas has proven efficient to improve completeness of the surveillance of dengue virus and captured up to $69 \%$ of cases [16].

At this stage, surveillance should be based primarily on laboratory confirmation. At EU level, new case definitions for dengue and chikungunya fever are being developed, based on the group discussion that took place during the meeting of ECDC Emerging and Vectorborne Diseases (EVD) network in December 2013 [17]. A case definition including only epidemiological and clinical criteria should be considered to monitor large outbreaks when systematic laboratory confirmation is not feasible any more.

The threat that the chikungunya outbreak in the western hemisphere represents for public health in Europe, should not overshadow the risk posed by other arboviruses such as dengue virus. Globalisation and environmental changes affect the dynamics of both viruses in Europe in the same way. Recent reports of limited autochthonous transmission of dengue virus and large-scale outbreaks in Europe call for continued vigilance and involvement [18-20]. When confronted with a febrile patient returning from tropical and subtropical areas, practitioners should now consider both diagnoses. Both mosquito-borne viral diseases can be tackled by the same surveillance and response efforts.

Laboratory capacity for CHIKV infections in the EU is limited and should be increased for early detection of cases. In 2007, the European Network for Diagnostics of 'Imported' Viral Diseases (ENIVD) conducted an external quality assurance survey of serological and molecular methods used for CHIKV detection [21]. That study unveiled great differences in the availability and performance of CHIKV diagnostics among the 24 participating laboratories from 15 countries across Europe. There is little available information to make us believe that the situation since has notably improved. Most of these laboratories are still using in-house techniques and may not be able to cope with a considerable increase in activity. New and reliable commercial serological and molecular tests are needed to improve access to CHIKV diagnostics in Europe.

CHIKV also represents a threat for blood safety in Europe. The recent detection of CHIKV among blood donors from Guadeloupe and Martinique in early 2014 alerts us to the risk of transfusion-transmitted infections [22]. Temporary deferral of donors returning from areas of active transmission of CHIKV is an effective way of preventing transfusion-transmitted infections. 
In case of local transmission of CHIKV in the EU, different measures should be considered according to the intensity of vector-borne transmission in the community. These measures include discontinuing blood collection in affected areas, screening donors for symptoms, post-donation quarantine and CHIKV RNA detection in donations.

In summary, the introduction of chikungunya in the Caribbean and the Americas illustrates how quickly diseases can spread with international travel. In the coming months, chikungunya cases among travellers visiting or returning to Europe are likely to increase. European public health authorities should therefore not underestimate the transmission potential of CHIKV and should remain vigilant. These imported cases could trigger local outbreaks in Europe where the competent vector is established. Levels of risk and preparedness appear very heterogeneous between and within countries. We believe that ECDC can lend support to EU Member States in preparing for potential local chikungunya outbreaks by building capacity and strengthening networks in collaboration with internationals stakeholders in this global event.

\section{Conflict of interest}

None declared.

\section{References}

1. Weaver SC, Reisen WK. Present and future arboviral threats. Antiviral Res. 2010;85(2):328-45. http://dx.doi.org/10.1016/j. antiviral.2009.10.008

2. Cassadou S, Boucau S, Petit-Sinturel M, Huc P, LeparcGoffart I, Ledrans M. Emergence of chikungunya fever on the French side of Saint Martin island, October to December 2013. Euro Surveill. 2014;19(13): pii=20752. http://dx.doi. org/10.2807/1560-7917.ES2014.19.13.20752

3. Schuffenecker I, Iteman I, Michault A, Murri S, Frangeul L, Vaney MC, et al. Genome microevolution of chikungunya viruses causing the Indian Ocean outbreak. PLoS Med. 2006;3(7):e263. http://dx.doi.org/10.1371/journal. pmed.0030263

4. Mavalankar D, Shastri P, Raman P. Chikungunya epidemic in India: a major public-health disaster. Lancet Infect Dis. 2007:7(5):306-7. http://dx.doi.org/10.1016/S1473-3099(07)70091-9

5. Rezza G, Nicoletti L, Angelini R, Romi R, Finarelli AC, Panning $M$, et al. Infection with chikungunya virus in Italy: an outbreak in a temperate region. Lancet. 2007;370(9602):1840-6. http:// dx.doi.org/10.1016/S0140-6736(07)61779-6

6. Grandadam M, Caro V, Plumet S, Thiberge JM, Souares Y, Failloux $A B$, et al. Chikungunya virus, southeastern France. Emerg Infect Dis. 2011;17(5):910-3. http://dx.doi.org/10.3201/ eid1705.101873

7. Cauchemez S, Ledrans M, Poletto C, Quenel P, de Valk H, Colizza V, et al. Local and regional spread of chikungunya fever in the Americas. Euro Surveill. 2014;19(28): $\mathrm{pii}=20854$.

8. Poletti P, Messeri G, Ajelli M, Vallorani R, Rizzo C, Merler S. Transmission potential of chikungunya virus and control measures: the case of Italy. PLoS One. 2011;6(5):e18860. http://dx.doi.org/10.1371/journal.pone.0018860

9. Boelle PY, Thomas G, Vergu E, Renault P, Valleron AJ, Flahault A. Investigating transmission in a two-wave epidemic of Chikungunya fever, Reunion Island. Vector Borne Zoonotic Dis. 2008;8(2):207-17. http://dx.doi.org/10.1089/vbz.2006.0620

10. Pan American Health Organization (PAHO). Number of reported cases of chikungunya fever in the Americas, by country or territory with autochthonous transmission 2013-2014 (to week noted). Epidemiological week / EW 26. Washington, D.C.:World Health Organization Regional Office for the Americas;
2014. Available from: http://www.paho.org/hq/index. php?option $=$ com_topics \&view $=$ article $\& i d=343 \&$ Itemid $=40931$

11. Paty MC, Six C, Charlet F, Heuzé G, Cochet A, Wiegandt A, et al. Large number of imported chikungunya cases in mainland France, 2014: a challenge for surveillance and response. Euro Surveill. 2014;19(28): pii=20856.

12. Requena-Méndez A, García C, Aldasoro E, Vicente JA, Martínez MJ, Pérez-Molina JA, et al. Cases of chikungunya virus infection in travellers returning to Spain from Haiti or Dominican Republic, April-June 2014 . Euro Surveill. 2014;19(28): $\mathrm{pii}=20853$.

13. European Centre for Disease Prevention and Control (ECDC). Rapid Risk Assessment. Chikungunya outbreak in Caribbean region, 25 June 2014. Stockholm: ECDC; 2014. Available from: http://ecdc.europa.eu/en/publications/Publications/ chikungunya-caribbean-june-2014-risk-assessment.pdf

14. European Commission. Decision No 1082/2013/EU of the European Parliament and of the Council of 22 October 2013 on serious cross-border threats to health and repealing Decision No 2119/98/EC. Official Journal of The European Union. Luxembourg: Publications Office of the European Union; 5 Nov 2013:L 293/1. Available from: http://eur-lex.europa.eu/ LexUriServ/LexUriServ.do?uri=0J:L:2013:293:0001:0015:EN:P DF

15. Napoli C, Salcuni P, Pompa MG, Declich S, Rizzo C. Estimated imported infections of Chikungunya and Dengue in Italy, 2008 to 2011. J Travel Med. 2012;19(5):294-7. http://dx.doi. org/10.1111/j.1708-8305.2012.00640.x

16. La Ruche G, Dejour-Salamanca D, Bernillon P, Leparc-Goffart I, Ledrans M, Armengaud A, et al. Capture-recapture method for estimating annual incidence of imported dengue, France, 2007-2010. Emerg Infect Dis. 2013;19(11):1740-8. http://dx.doi. org/10.3201/eid1911.120624

17. European Centre for Disease Prevention and Control (ECDC). Meeting report. EVD Network and Coordination Group annual meeting. Stockholm, 4-5 December 2013. Stockholm: ECDC; 2013 May. Available from: http://www.ecdc.europa.eu/en/ publications/Publications/emerging-vectorborne-diseasesannual-network-meeting-2013.pdf

18. Gjenero-Margan I, Aleraj B, Krajcar D, Lesnikar V, Klobucar A, Pem-Novosel I, et al. Autochthonous dengue fever in Croatia, August-September 2010. Euro Surveill. 2011;16(9):pii=19805.

19. La Ruche G, Souares Y, Armengaud A, Peloux-Petiot F, Delaunay P, Despres $P$, et al. First two autochthonous dengue virus infections in metropolitan France, September 2010. Euro Surveill. 2010;15(39): pii=19676.

20. Sousa C, Clairouin M, Seixas G, Viveiros B, Novo M, Silva A, et al. Ongoing outbreak of dengue type 1 in the Autonomous Region of Madeira, Portugal: preliminary report. Euro Surveill. 2012;17(49): $\mathrm{pii}=20333$.

21. Donoso MO, Niedrig M. Laboratory capacity for detection of chikungunya virus infections in Europe. Euro Surveill. 2007;12(9): $\mathrm{pii}=3267$.

22. Gallian P, de Lamballerie X, Salez N, Piorkowski G, Richard P, Paturel L, et al. Prospective detection of chikungunya virus in blood donors, Caribbean 2014. Blood. 2014;123(23):3679-81. http://dx.doi.org/10.1182/blood-2014-03-564880 